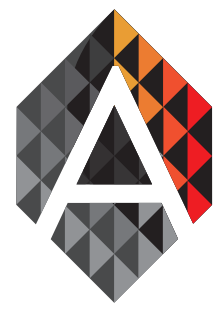

ADCAIJ: Advances in Distributed Computing and Articial Intelligence Journal Regular Issue, Vol. 6 N. 1 (2017), 41-50

eISSN: $2255-2863$

DOI: http://dx.doi.org/10.14201/ADCAIJ2017614150

\title{
Manufacturing processes in the textile industry. Expert Systems for fabrics production
}

\author{
J. Bullón Pérez ${ }^{\mathrm{a}}$, A. González Arrieta ${ }^{\mathrm{b}}, \mathrm{A}$. Hernández \\ Encinas $^{\mathrm{c}}$, and A. Queiruga-Dios ${ }^{\mathrm{c}}$ \\ ${ }^{\mathrm{a}}$ Chemical and Textile Engineering Department, University of Salamanca, Spain \\ ${ }^{\mathrm{b} C}$ Computer Sciences and Control Department, University of Salamanca, Spain \\ 'Applied Mathematics Department, University of Salamanca, Spain perbu,angelica,ascen, \\ queirugadios@usal.es
}

$\begin{array}{ll}\text { KEYWORD } & \text { ABSTRACT } \\ \begin{array}{l}\text { Expert Systems; } \\ \text { Case Based }\end{array} & \begin{array}{l}\text { The textile industry is characterized by the economic activity whose objective is the } \\ \text { Reasoning; }\end{array} \\ \text { Textile Industry; } ; & \text { tion, as well as technical and industrial purposes. Within manufacturing, the Textile is } \\ \text { Industry 4.0. } & \text { one of the oldest and most complex sectors which includes a large number of sub-sec- } \\ \text { tors covering the entire production cycle, from raw materials and intermediate prod- } \\ \text { ucts, to the production of final products. Textile industry activities present different } \\ \text { subdivisions, each with its own traits. The length of the textile process and the variety } \\ \text { of its technical processes lead to the coexistence of different sub-sectors in regards } \\ \text { to their business structure and integration. The textile industry is developing expert } \\ \text { systems applications to increase production, improve quality and reduce costs. The } \\ \text { analysis of textile designs or structures includes the use of mathematical models to } \\ \text { simulate the behavior of the textile structures (yarns, fabrics and knitting). The Finite } \\ \text { Element Method (FEM) has largely facilitated the prediction of the behavior of that } \\ \text { textile structure under mechanical loads. For classification problems Artificial Neu- } \\ \text { ral Networks (ANNs) have proved to be a very effective tool as a quick and accurate } \\ \text { solution. The Case-Based Reasoning (CBR) method proposed in this study comple- } \\ \text { ments the results of the finite element simulation, mathematical modeling and neural } \\ \text { networks methods. }\end{array}$

\section{Introduction}

Textile and clothing activities present different subdivisions, each with its own traits. The length of the textile process and the variety of its technical processes lead to the coexistence (within the textile and clothing sector) of different sub-sectors in regards to their business structure and integration.

Defined by its fragmentation and heterogeneity, the textile industry includes mainly small and medium companies, some of them highly specialized in specific processes. Among the factors of its complexity the large amount of raw materials used in the manufacture of fibres (cotton, wool, synthetic materials, etc.) and the

J. Bullón Pérez, A. González Arrieta, A. Hernández Encinas, and A. Queiruga-Dios

Manufacturing processes in the textile industry.

Expert Systems for fabrics production
ADCAIJ: Advances in Distributed Computing and Articial Intelligence Journal Regular Issue, Vol. 6 N. 1 (2017), 41-50 elSSN: 2255-2863 - http://adcaij.usal.es (๑) Ediciones Universidad de Salamanca - CC BY-NC-ND 
diversity of production processes necessary to obtain them must be emphasized. Furthermore, the textile industry can be classified in several ways depending on the production process, the obtained final products achieved, etc. In the specific case of textile fabrics, the process starts with the gathering of natural fibres or artificial or synthetic production. Then, after spinning process (if needed), continues with the processing into textile flat structures, fabrics or cloths, in the form of woven fabrics, knitted or mesh, nonwovens, etc. The fabrics or textiles are commonly treated in finishing processes, including dyeing or printing processes, coating, rolling or

mechanical finishing, which give new properties to the fabric before the next stage: the clothing stage.

Production planning is a complex area of any manufacturing operation. In textiles, planning is complicated as there exists different types of fibres, yam counts, spinning systems, preparation methods, and end products. All of these factors, combined with the customer's demands for correctly filled orders and short delivery times, make the production planning process more complicated. In addition, effective production planning in the textile industry has become more and more critical as intense foreign competition has impacted the market (Bullón Pérez et al., 2016).

Fabric engineering activities are increasingly based on computational models that aim the prediction of the properties and the performance of the fabrics under consideration. Different computational tools have been used in order to represent the fabrics in a computational environment and to predict their final properties. Among others, FEM analysis has mainly supported the prediction of the behavior of the complex textile structures under mechanical loads (Chen, 2009). In the case of classification problems ANNs have been proved to be a very efficient tool for a fast and precise solution (Guruprasad, 2010).

The textile industry is gradually developing expert system applications to increase production, improve quality and reduce costs. Such systems are surfacing in a variety of areas throughout the textile manufacturing process. This important decision scenario in the textile industry generates a sequence of production planning decisions necessary to produce a specific category of end product. This sequence begins with the decision to produce a particular type of end product. Then the appropriate fibre type is chosen, following the appropriate yarn and the appropriate spinning system; and finally, the appropriate preparation method is selected. Each decision in the sequence depends on the combination of the decisions taken in the preceding stages.

The outline of this paper is as follows. In Section 2, the textile fabrication processes along the textile production chain will be presented, starting with fibre and yarn production processes until the general principles. The section continues with the basics of fabric production technologies, and ends with textile finishing and clothing industry. In Section 3, the Case Based Reasoning method is specified for the textile industry, and finally, in Section 4, some conclusions are included.

\section{The textile fabrication processes and technologies}

The textile and clothing industry includes activities such as the treatment of raw materials, i.e. the preparation or production of various textile fibres, and/or the manufacture of yarns through spinning (the production of the «Natural» fibres and the «Man-made» fibres). Other actions within the textile and clothing industry are the production of knitted and woven fabrics (i.e. knitting and weaving); the finishing activities, aimed at giving fabrics the visual, physical and aesthetic properties which consumers demand (bleaching, printing, dyeing, impregnating, coating, plasticizing, etc.); and finally, the transformation of those fabrics into products such as garments, knitted or woven (the so-called «clothing» industry), carpets and other textile floor coverings, home textiles (bed linen, table linen, toilet linen, kitchen linen, curtains, etc), and technical or «industrial» textiles. The first step in the textile process chain is the production of fibres. The world of fibre materials is divided into natural and man-made fibres. The Regulation (EU) No 1007/2011 of the European Parliament and of the Council of 27 September 2011, on textile fibre names and related labelling and marking of the fibre composition of textile products, aligns laws in all European Union countries, protecting consumer interests, and reducing the risk of fraud. This Regulation shall apply to textile products when made available on the Union market and to the textile products.

In the area of natural fibre materials, they can be classified according to their source, such as cellulosic (from plants), protein (from animals), and mineral. Plant fibers may be seed hairs, such as cotton; bast (stem) fibers,

J. Bullón Pérez, A. González Arrieta, A. Hernández Encinas, and A. Queiruga-Dios

Manufacturing processes in the textile industry.

Expert Systems for fabrics production
ADCAIJ: Advances in Distributed Computing and Articial Intelligence Journal Regular Issue, Vol. 6 N. 1 (2017), 41-50 eISSN: 2255-2863 - http://adcaij.usal.es (c) Ediciones Universidad de Salamanca - CC BY-NC-ND 
such as linen; leaf fibers, such as sisal; and husk fibers, such as coir from the coconut. Animal fibers include wool, hair, fur, and secretions, like silk. The natural fibre materials most commonly used are cotton and wool. The only important mineral fiber is asbestos; but due to its associated health problems it is of few economic consequences nowadays (FAO, 2009).

The first step in the processes suggested in (Palma Morón, 1994) is that the fibres are separated from the seeds and other materials like capsule fragments, leaves, twigs and dirt. In a carding machine the fibres are combed by a series of rotating drums and moving carding bars are equipped with metal combing teeth. As a result, a soft uniform fibre band is formed. In the fibre band, called sliver, the fibres lie parallel to each other. The sliver is held together by the friction between the parallel fibres, which provides just enough tenacity for subsequent production steps. During the spinning process, the transition from a loose fibre bundle to an actual yarn takes place. The bundle of parallel fibres is twisted, which gives the yarn its tenacity. The predominant spinning technologies, which have been established in the industry are ring spinning, open-end spinning and airjet spinning.

Rayon is the generic term for fibre (and the resulting yarn and fabric) and was the first manufactured fibre of regenerated cellulose and is not synthetic. Man-made fibres are divided into two types: viscose and related cellulose-based fibres; and synthetic fibres like polyester, nylon and acrylic. In their initial state, the fiber-forming polymers are solids and therefore they must be first converted into a fluid state for extrusion. The fiber forming substance is made temporal fluid extruded through spinneret and then return to solid state (by solidifying) in fiber form. There are mainly three types of spinning as: melt spinning, wet spinning and dry spinning.

Textile fabrics are most commonly woven but may also be produced by knitting, felting, lace making, net making, nonwoven process and tufting or a combination of this processes. In the weaving process, two yarn systems are used, warp and weft thread, that are interlaced and lie at right angles to each other. The threads that run along the length of the fabrics (in the direction of production) are know as warp ends whilst the threads that the weft threads are oriented perpendicular to the direction of production. There are several methods for inserting the weft thread into the fabric, the most common being shuttle, rapier and airjet technology. The fabric weave or design is the manner in which the warp and weft are interlaced. The pattern or repeat is the smallest unit of the weave which when repeated it will produce the design required in the fabric. The number of wave structures that can be produced is practically unlimited. The most common standard weave patterns are plain, twill and atlas weave.

Knitting is the most common method of interlooping and manufacturing textile products. It requires a relatively fine, smooth, strong yarn with good elastic recovery properties. The worsted system has proved particularly suitable for spinning yarns used for knitwear, outerwear and socks, and the combed cotton system for underwear, sportswear and socks. The development of synthetic fibres and of their texturing processes has been proved particularly beneficial to the knitting industry and has resulted in a close association between the two industries. In (Spencer, 2001) the term knitting describes the technique of constructing textile structures by forming a continuous length of yarn into columns of vertically intermeshed loops includes two main textile techniques, weft and warp knitting. The difference between weft and warp knitting originates in the way the needles move during the production and in the way the yarn is supplied. Weft knitting is a one fibre technique, which means that only one fibre is needed to build the stitches. The needles are moved separately, whereas the warp knitting needles are moved simultaneously. Therefore, all needles need the fibre material at the same time. For this reason, the yarn is supplied with the help of warp beams. The most important knitwear fabrics are circular knitted, warp knitted, flat- knitted fabrics and fully-fashioned fabrics. Depending on the angle of take off of the fabric from the needle and also on the pattern possibilities, it is possible to divide warp-knitting machines into two different types: warp-knitting machines and Raschel warp-knitting machines. Weft knitting is the more diverse, widely spread and larger of the two sectors, and represents around one quarter of the total of apparel fabric compared with about one sixth for warp knitting. Weft knitting machines, particularly of the garment-length type, are attractive to small manufacturers because of their versatility, relatively low total capital costs, small floor space requirements, quick pattern and machine changing facilities, and the potential for short production runs and low stock-holding requirements of yarn and fabric.

Braiding is a fabric production method, which requires at least three yarns. By intertwining the yarns alternately following a certain algorithm, the braid is formed. Braids can be defined as «areal or voluminous bodies

J. Bullón Pérez, A. González Arrieta, A. Hernández Encinas, and A. Queiruga-Dios

Manufacturing processes in the textile industry.

Expert Systems for fabrics production
ADCAIJ: Advances in Distributed Computing and Articial Intelligence Journal Regular Issue, Vol. 6 N. 1 (2017), 41-50 eISSN: 2255-2863 - http://adcaij.usal.es (c) Ediciones Universidad de Salamanca - CC BY-NC-ND 
with a regular thread density and a closed product surface, whose braid bobbin yarns are intertwined diagonally towards the product edge». In contrast, the threads in a woven fabric are intertwined in a perpendicular fashion towards the product edge and can have a biaxial or a triaxial structure (Eichhoff, 2012).

The finish is a treatment given to a fabric, to change its appearance, handling-touch or performance. Its purpose is to make the fabric more suitable for its end use and includes any general treatment given to clean and iron fabrics and create exclusive variations of them by using chemical treatments, dyeing, printing, etc. to make fabric attractive and appealing. Fabric preparation has been subdivided into singeing, desizing, scouring, bleaching, mercerizing, carbonizing and heat setting. Finishing is broken down into chemical and mechanical process. Chemical finishing covers those treatments that alter the performance of the textile fabric where the chemical is the major component of the change. Mechanical finishing refers to certain types of mechanical devices that physically alters the fabric. Textile finishes are important because of the following reasons: The finishes help to improve the appearance of fabric and enhance its looks; produce variety in fabrics through dyeing and printing; improve the feel or touch of fabric; make the fabric more useful; improve the draping ability of light weight fabrics and make fabric suitable for an end (specific) use.

Finishes are all the processes through which fabric is passed after bleaching, dyeing, or printing in preparation for market and use, and they are categorized based on:

- Durability: permanent, durable, semi-durable, non-durable.

- Application method: thermal, chemical, mechanical.

- Purpose: routine, aesthetic, functional.

The following are the durability categories for finishes: A permanent finish lasts for the life of the fabric. A durable finish lasts for the expected life of the product; finish effectiveness gradually diminishes after repeated laundering or cleaning. A semi-durable finish loses effectiveness after repeated laundering and use and must be reapplied. A non-durable finish such as starch is partially or completely removed after one laundering or cleaning.

In the textile manufacturing process, finishes are classified according to the application method:

- Thermal finish: heat is applied to thermoplastic materials to produce a desired effect, i.e., permanent pleats in thermoplastic materials.

- Chemical finishes: fabric is chemically reacted with the finish to produce a desired effect. Application may result in changes in other properties (tear or tensile strength); chemical finishes are applied under very controlled conditions, i.e., durable press finish.

- Mechanical finishes: fabric is subjected to mechanical action to produce a desired effect; mechanical and chemical finishes are combined for some applications, i.e., napping of flannel fabric.

The textiles and clothing sectors can be seen as a supply chain consisting of a number of discrete activities. Increasingly the supply chain from sourcing of raw materials via design and production to distribution and marketing is being organized as an integrated production network where the production is sliced into specialized activities and each activity is located where it can contribute to increase to the value of the end product. When the location decision of each activity is being made, costs, quality, reliability of delivery, access to quality inputs and transport and transaction costs are important variables.

The basic production technology of the apparel industry has not changed much over the past century, and it is characterized by the progressive bundle system. Work is organized such that each worker is specialized in one or a few operations. The fabric is first cut and then grouped by parts of the garment, tied into bundles (pre-assembly) and then sewed together. The individual sewing tasks are organized in a systematic fashion and specialized sewing machines have been developed for the individual tasks. A worker receives a bundle of unfinished garments, performs her single task and places the bundle in a buffer.

J. Bullón Pérez, A. González Arrieta, A. Hernández Encinas, and A. Queiruga-Dios

Manufacturing processes in the textile industry.

Expert Systems for fabrics production
ADCAIJ: Advances in Distributed Computing and Articial Intelligence Journal Regular Issue, Vol. 6 N. 1 (2017), 41-50 eISSN: 2255-2863 - http://adcaij.usal.es (c) Ediciones Universidad de Salamanca - CC BY-NC-ND 


\section{CBR and the Textile Industry}

There are several research papers focus on the efficiency of the Computer Aided Design (CAD) tools in the textile industry (see, for instance (Bingham and Hague, 2013) and (Chattopadhyay and Guha, 2004)). This efficiency can be determined by the decrease of the production time of a same collection regarding the traditional method; the reduction of physical prototype tests; the reliability (the capacity of decision grew); the flexibility (the capacity rectification becomes agile); the creativity: accentuating the ability to manifest the creativity of designers, related to the concept of unevenness (Green, 1989), deviation of ideas in the process of creation; and the organization process: including organization reinforcements of the products creating processes that allow the transmission or correct information in each state of creation (suitable formats and presentations). Quality control from the beginning of the whole process (see (Dwivedi and Dwivedi, 2013) and (Fontana et al., 2005)). More necessary and important than simulations is to connect this simulation with the production systems because:

- It is considered that the computer simulation systems do not allow to make reliable decisions about what would be the final product.

- It is still necessary for sale the creation of a sample, since simulations are not accepted in the current culture of the market.

- The application of CAD tools does not prevent knitting prototypes, but they reduce their number, and discard those that are not satisfactory.

- The simulation of fabrics, raw material, colorful, structures are not precise enough.

Concerning the industrial processes and the systems simulations, the latest trends in database development and the use of a CAD system are based on the advice of a system of Artificial Intelligence (AI). And more specifically the use of CBR is concerned with the analysis or solution of problems based on previous cases (Kolodner, 2014).

Due to the complex structure of the textile and the commodity difficulties added, it is not possible to use accurate models for analysis design. Therefore these textile engineering increasingly rely on the use of computational tools, whose approximate models predict the properties and behavior of textile structures.

Humans solve many problems by reasoning with previous cases: Lawyers use in their arguments the verdict of previous cases; doctors look for sets of symptoms that identify patients pathologies with a set of previous cases; engineers base many of their new projects in solutions which have already been carried out, and experts programmers reuse more or less abstract schemes of previously obtained solutions.

Therefore, the idea of CBR scheme is to use some methods of AI that allow the approach of these parameters of the process, learn from the past of such processes. Creating a database that will grow over time as more products are manufactured. Each industry produces different products and each product can have different associated processes.

The Case Based Reasoning is a methodology that uses different technologies for building expert systems, and it can propose solutions in domains that are not fully understood. Moreover, it allow the evaluation of solutions when there is no algorithmic method, it is easier for it to acquire new cases, and to discover new rules and generalizations. CBR is faster than other methodologies, as is faster to reuse a solution than to get the solution from scratch. The cases in CBS help a reasoner to concentrate on the important aspects of a problem and to identify the defining characteristics. Cases can also provide «negative information», warning of possible failures (exceptions). Finally, this methodology maintains the knowledge base, since users can add new cases without expert help.

CBR solves a problem by adapting solutions previously given to similar problems (Riesbeck and Schank, 2013). Furthermore, as the CBR memory stores a number of problems with their solutions, the solution of a new problem is obtained recovering cases stored in the memory. Therefore a case encompasses a given problem and the solution to this problem.

J. Bullón Pérez, A. González Arrieta, A. Hernández Encinas, and A. Queiruga-Dios

Manufacturing processes in the textile industry.

Expert Systems for fabrics production
ADCAIJ: Advances in Distributed Computing and Articial Intelligence Journal Regular Issue, Vol. 6 N. 1 (2017), 41-50 eISSN: 2255-2863 - http://adcaij.usal.es (c) Ediciones Universidad de Salamanca - CC BY-NC-ND 
In this research, focuses in the textiles manufacturing processes, the problem starts when a user wants to create a new textile product and he or she asks for a suitable solution satisfying as much as possible his or her requirements on the process parameters. Hence, the idea is to use some AI method to approximate these process parameters, learning from the past executions of this kind of processes.

All in all, an AI method which supports the incremental, non-dependent and predictive power properties is needed. Incremental property is related to the fact that the algorithm should adapt itself along the time with the new data. Non-dependent of any parameter, means that each query can contain different parameters and the relevance of these parameters can change depending on the user requirements. an finally, the AI method should be able to predict more than one parameter.

These features point to a flexible methodology like Case Based Reasoning. As the CBR is a lazy learning approach, its allows that the algorithm will not be influenced by any parameter, and can be adapted to any new situation giving more importance to some parameters than others. Besides, the implementation of CBR can be enough open to allow the prediction of more than one parameter (Villanueva and Sánchez-Marré, 2012).

Moreover, textile end users are not interested in a general model which generalize all the data, but in a particular solution proposed for the particular query that they are requesting.

Another point to take in to account is that our system must support more than one attribute belonging to the solved problem, and this classification between description and solution can vary on demand. In CBR literature, some hybrid solutions have been found to face up with the reuse step, but most of them are oriented to solve only one solution attribute.

Most of the proposals use techniques from supervised learning and have only one attribute to predict (FdezRiverola and Corchado, 2000). Such is the case of a system to predict oceanographic temperatures (Corchado and Lees, 2001). This system retrieves the most similar cases and retrains a radial basis network with them to create a new solution.

Another CBR approach that handles a solution with more than one attribute is the case completion CBR detailed in (Burkhard, 2004), but the attributes are predefined to belong to the description or the solution part. It handles more than one attribute to solve, but in this case, they solve them step by step. As they are dealing with domains that have predefined and well-known attribute dependencies, the order in the steps is derived from those dependencies.

In CBR recommended literature, the compromise-driven retrieval can bee found in (McSherry, 2003) and (McSherry, 2006). This concept allows to extend the query specification including rules for numerical attributes: Less-is-Better and More-is-Better. A typical CBR system consists of four sequential steps that are invoked whenever it is necessary to solve a problem (Kolodner, 2014). Figure 1 shows the CBR applied to Textile Industry. A textile process involves the transformation of the fibers by mechanical action into a final product, that is, equipment and materials: raw material inlet and outlet tissue or product. These elements can be described by parameters or attributes. Consequently, the process can be described as an attribute-list-value.

The development of a rapid configuration system for textile production machinery based on the physical behavior simulation of precision textile structures system can be found in the MODSIMText project (MODSIMText, 2008). This system was born to be a tool for helping to adjust the parameters of a process and starts when a user

J. Bullón Pérez, A. González Arrieta, A. Hernández Encinas, and A. Queiruga-Dios

Manufacturing processes in the textile industry.

Expert Systems for fabrics production
ADCAIJ: Advances in Distributed Computing and Articial Intelligence Journal Regular Issue, Vol. 6 N. 1 (2017), 41-50 eISSN: 2255-2863 - http://adcaij.usal.es (c) Ediciones Universidad de Salamanca - CC BY-NC-ND 


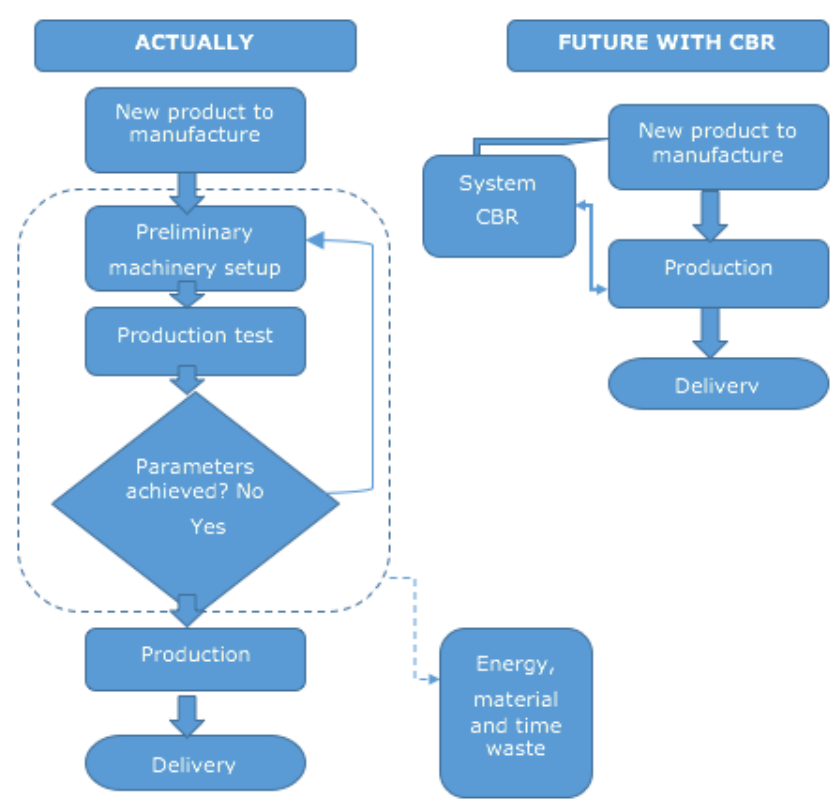

Figure 1: CBR applied to Textile Industry

wants to create a new product. The user should specify some of the parameters to obtain the required product. These parameters can belong to the raw material, to any machine in the process or to the final product. So, with an AI method it is possible to approximate the rest of the parameters learning from the past executions of this kind of process.

In this system for textile production machinery more than one parameter must be predicted and depending on the query, these parameters are not always the same. Moreover, these could change any time that there is a new query. Besides, the database will grow as more process executions are finished.

In addition, some of these parameters have extra information that can be used to know its value in a determinate situation like the parameters that can be defined by a predefined empirical formula. So these parameters are not going to be predicted, because it is more reliable the exact value. Another kind of information that guides the predicting process is the knowledge of the relations among parameters.

The solution adopted in this study was the Case Based Reasoning. CBR is a problem solving paradigm that uses the human reasoning model as a base: humans use past experiences to solve new situations or problems.

This solving paradigm is based in collecting a lot of relevant cases that are the past experiences of the system.

The CBR consists on:

- To gather the problem description by the user.

- To measure the similarity of the current problem to previous problems stored in a case base (or memory) with their known solutions, retrieving one or more similar cases.

- To adapt (reuse) the solution of one or more of the retrieved cases, possibly after adapting it to account for differences in problem descriptions.

J. Bullón Pérez, A. González Arrieta, A. Hernández Encinas, and A. Queiruga-Dios

Manufacturing processes in the textile industry.

Expert Systems for fabrics production
ADCAIJ: Advances in Distributed Computing and Articial Intelligence Journal Regular Issue, Vol. 6 N. 1 (2017), 41-50 eISSN: 2255-2863 - http://adcaij.usal.es (c) Ediciones Universidad de Salamanca - CC BY-NC-ND 


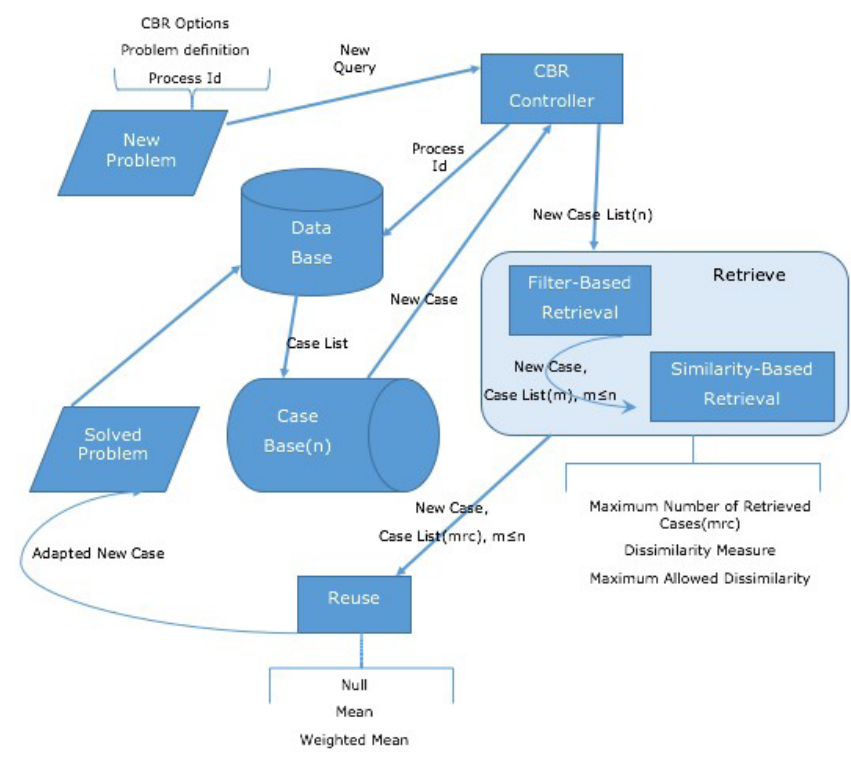

Figure 2: The life cycle of CBR applied to Textile Industry

- To evaluate (revise) by the expert the solution proposed by the system.

- The problem description and its new solution can be retained (stored) as a new case, and the system has learnt to solve a new problem.

In MODSIMText project, the last two points has been discarded, due to the fact that the project cannot rely on this (as it cannot be assure) it will be done or at least, done with a minimum quality (see Figure 2).

On the other hand, the CBR software has 4 phases: Retrieve, Reuse, Revise Retain.

- The Retrieve phase involves finding the most similar cases to a given case. This task starts with a problem description and ends when best matching previous case has been found. It is usual to divide this task in two parts. The first one tries to select similar cases and the second one chooses the best matches. The similarity is a function that gives a scalar distance between two arguments (case element and case problem). This value is also calculated with a weight given for each parameter.

- The Reuse phase is the most complex tasks in the CBR cycle. It is a phase based on the principle: Similar problems have similar solutions.

- The Revise and the Retain phases have been discarded, as previously mentioned, due to the fact that the system cannot rely whether the expert has revised and evaluated the solution provided by the system.

\section{Conclusions}

The expert systems, with applications in textile industry, is accompanied by decentralized control paradigms that result from the system design of the distributed systems arising here, their targeted adaptivity to unexpected events, and the high changeability of the components. Decentralized control paradigms are not yet very well spread in the industrial context. On the one hand, this is because, while the underlying theoretical models are old, practical insights, evidence, and architectures have only been possible since the availability of high computing power. At the same time, however, it is precisely the decentralized control systems that open up room for new increases in efficiency through greater flexibility and adaptivity. Their impact in the manufacturing processes in the textile companies could be detailed as follows:

J. Bullón Pérez, A. González Arrieta, A. Hernández Encinas, and A. Queiruga-Dios

Manufacturing processes in the textile industry.

Expert Systems for fabrics production
ADCAIJ: Advances in Distributed Computing and Articial Intelligence Journal Regular Issue, Vol. 6 N. 1 (2017), 41-50 elSSN: 2255-2863 - http://adcaij.usal.es (c) Ediciones Universidad de Salamanca - CC BY-NC-ND 
- Detection of defects or other problems that may appear during the subsequent manufacturing process.

- Integration of the simulation results and parameters into the textile machinery for the rapid configuration of the machine as well as the precision manufacturing of the virtual textile structures developed using this software.

- The conventional visualization and design tools don't bring added value since they are of little help to design multifunctional technical textiles. The company that follows this pattern is only able to offer conventional textile products. The capacity to design any kind of multifunctional textiles has a great impact in the capacity to offer added-value from the company and its products.

- The improvement in the speed and flexible development of new technical textile products. The simplification of the production process to obtain such products increases the rate of new products and at the same time successfully finding a niche market, and covering new society necessities, and giving added-value opportunities to the textile companies

The use of digital technologies, and in a world of smart devices, will change the way we produce textiles. Machines with additional sensors, actors and cognition acting in a network can lead to the fourth industrial revolution: Industry 4.0.

The scenarios are explored using currently available technology to build smart textile systems, such as wireless communications, textile antennas, chromic display materials, textile switches, textile pressure and gesture sensors, textile circuits, and micro-component welding technology.

Future industrial applications will need to be developed at a rapid pace in order to capture the agility required by modern businesses. Typical industrial software development approaches will need to be adjusted to the new paradigm of distributed complex system software with main emphasis on collaboration and multi-layer interactions among systems of systems, which is challenging. To do so, some generic common functionality will need to be provided, potentially by a distributed service platform hosting common functionalities, following the service-oriented architecture approach (Bullón Pérez et al., 2016).

\section{Acknowledgments}

We would like to thank Ana Bullón Carbajo for her language advice.

\section{References}

Bingham, G. A. and Hague, R., 2013. Efficient three dimensional modelling of additive manufactured textiles. Rapid Prototyping Journal, 19 (4):269-281.

Bullón Pérez, J., González Arrieta, A., Hernández Encinas, A., and Queiruga-Dios, A., 2016. Industrial Cyber-Physical Systems in Textile Engineering. In International Conference on EUropean Transnational Education, pages 126-135. Springer.

Burkhard, H. D., 2004. Case completion and similarity in case-based reasoning. Computer Science and Information Systems, 1 (2):27-55.

Chattopadhyay, R. and Guha, A., 2004. Artificial neural networks: applications to textiles. Textile Progress, 35 (1):1-46.

Chen, X., 2009. Modelling and predicting textile behaviour. Elsevier.

Corchado, J. M. and Lees, B., 2001. A hybrid case-based model for forecasting. Applied Artificial Intelligence, 15 (2):105-127.

Dwivedi, A. and Dwivedi, A., 2013. Role of Computer and Automation in Design and Manufacturing for Mechanical and Textile Industries: CAD/CAM. International Journal of Innovative Technology and Exploring Engineering (IJITEE), 3 (3):8.

J. Bullón Pérez, A. González Arrieta, A. Hernández Encinas, and A. Queiruga-Dios

Manufacturing processes in the textile industry.

Expert Systems for fabrics production
ADCAIJ: Advances in Distributed Computing and Articial Intelligence Journal Regular Issue, Vol. 6 N. 1 (2017), 41-50 elSSN: 2255-2863 - http://adcaij.usal.es (c) Ediciones Universidad de Salamanca - CC BY-NC-ND 
Eichhoff, J., 2012. Data-transmitting Textile Fibre Ropes for Firefighting Applications. Shaker. FAO, 2009. International Year of Natural Fibres 2009. Trade and Markets Division (EST).

Fdez-Riverola, F. and Corchado, J., 2000. Sistemas híbridos neuro-simbólicos: Una revisón. Inteligencia artificial: Revista Iberoamericana de Inteligencia Artificial, 4 (11):12-26.

Fontana, M., Rizzi, C., and Cugini, U., 2005. 3D virtual apparel design for industrial applications. ComputerAided Design, 37 (6):609-622.

Green, T. R., 1989. Cognitive dimensions of notations. People and computers V, pages 443-460. Guruprasad, R., 2010. Soft computing in textiles. Indian Journal of Fibre \& Textile Research, 35:75. Kolodner, J., 2014. Case-based reasoning. Morgan Kaufmann.

McSherry, D., 2003. Similarity and compromise. In International Conference on Case-Based Reasoning, pages 291-305. Springer.

McSherry, D., 2006. Completeness criteria for retrieval in recommender systems. In European Conference on Case-Based Reasoning, pages 9-29. Springer.

MODSIMText, P., 2008. Development of a rapid configuration system for textile production machinery based on the physical behaviour simulation of precision textile structures. FP7 EU Research project. Grant Agreement NMP2-SL-2008-214181.

Palma Morón, F., 1994. Operaciones fundamentales en la hilatura de fibras textiles. Hespérides. Riesbeck, C. K. and Schank, R. C., 2013. Inside case-based reasoning. Psychology Press.

Spencer, D. J., 2001. Knitting technology: a comprehensive handbook and practical guide, volume 16. CRC Press.

Villanueva, B. S. and Sánchez-Marré, M., 2012. Case-based reasoning applied to textile industry processes. In International Conference on Case-Based Reasoning, pages 428-442. Springer.

J. Bullón Pérez, A. González Arrieta, A. Hernández Encinas, and A. Queiruga-Dios

Manufacturing processes in the textile industry.

Expert Systems for fabrics production
ADCAIJ: Advances in Distributed Computing and Articial Intelligence Journal Regular Issue, Vol. 6 N. 1 (2017), 41-50 eISSN: 2255-2863 - http://adcaij.usal.es (c) Ediciones Universidad de Salamanca - CC BY-NC-ND 